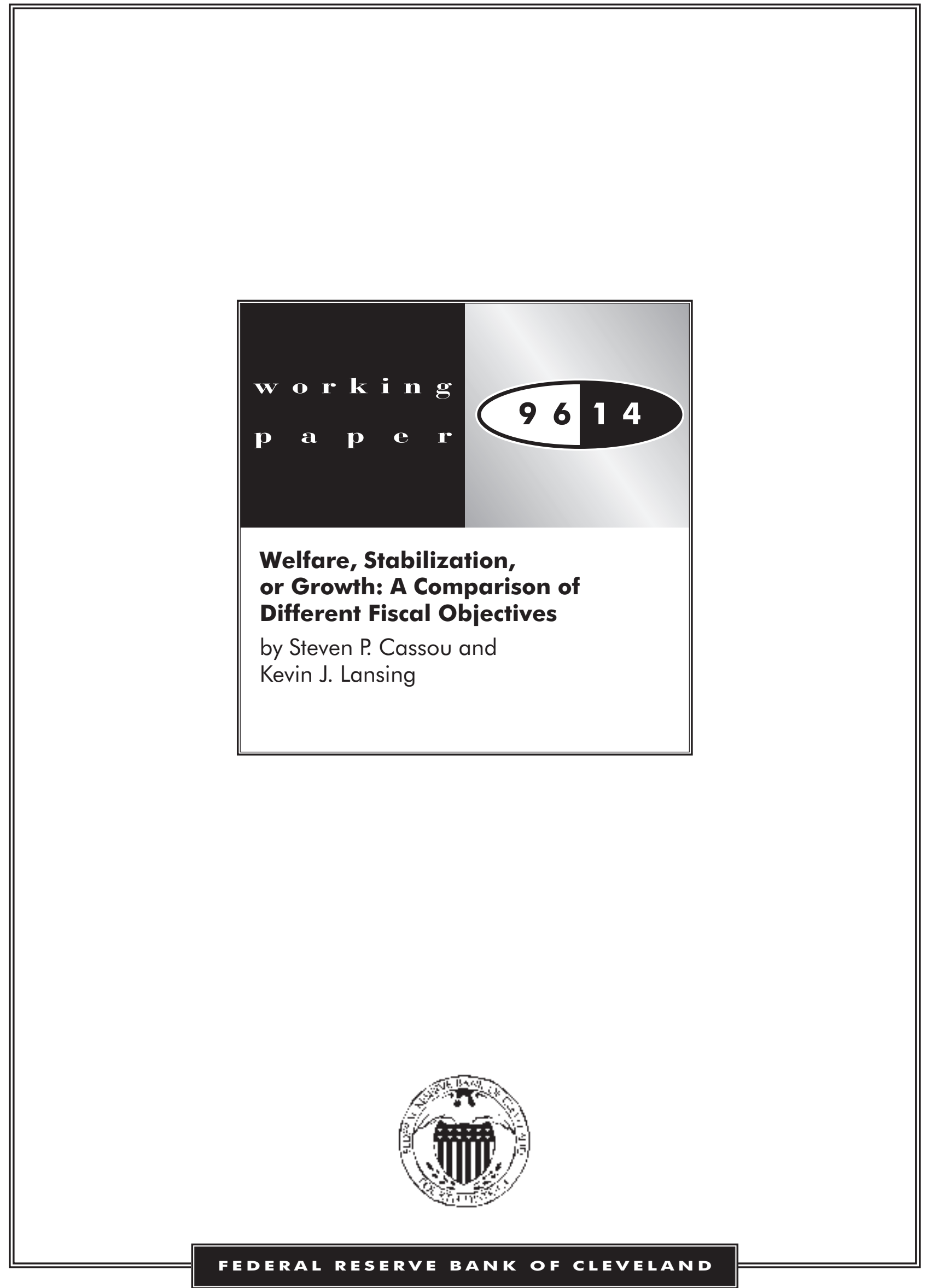


Working Paper 9614

\section{WELFARE, STABILIZATION, OR GROWTH: A COMPARISON OF DIFFERENT FISCAL OBJECTIVES}

by Steven P. Cassou and Kevin J. Lansing

Steven P. Cassou is an assistant professor of economics at Kansas State University, and Kevin J. Lansing is an economist at the Federal Reserve Bank of Cleveland. The authors would like to thank Franck Portier for encouraging this project and James Dolmas for helpful comments.

Federal Reserve Bank of Cleveland working papers are preliminary materials distributed to promote discussion and critical comment on research in progress. These papers may not have been subject to the formal editorial review accorded the Bank's official publications.

The views stated herein are those of the authors and are not necessarily those of the Federal Reserve Bank of Cleveland or of the Board of Governors of the Federal Reserve System.

Working papers are now available electronically through the Bank's home page on the World Wide Web:

http://www.clev.frb.org.

December 1996 


\begin{abstract}
This paper investigates a variety of objectives that are commonly used to motivate government fiscal action. These include, welfare maximization, stabilization and growth maximization. The policies are compared on the basis of their implications for welfare, volatility and growth. We show that stabilization policies can produce welfare levels that are nearly identical to those of welfare maximization policies and that both welfare maximization and stabilization policies yield large welfare gains and modest growth losses relative to growth maximization policies. We also show that there are side issues to stabilization polices. In particular: (1) It is not possible to stabilize all macroeconomic variables simultaneously, even when the number of policy instruments is equal to the number of shocks; (2) stabilizing a particular variable requires increased volatility of some other variable; (3) stabilization requires some flexibility regarding the government's budget constraint; and, (4) stabilization requires the government to respond in a precise and immediate way to exogenous shocks which hit the economy.
\end{abstract}




\section{Introduction}

The ability of the federal government to affect the economy has long been recognized. This has led many economists and policymakers to call on the government to undertake responsibility for managing various aspects of the economy. These responsibilities range from micro-management of specific farm product markets to broad management of aggregate GDP. In this paper, we investigate a variety of popular broad fiscal policy objectives, including, welfare maximization, stabilization and growth maximization. The various objectives are compared on the basis of their implications for welfare, volatility and growth. In addition, we consider the political feasibility of executing the policy rules that each of the objectives require.

The framework for our analysis is an analytically tractable endogenous growth real business cycle model that allows closed form decision rules for households and the government. The model is similar to one used by Hercowitz and Sampson (1991) to integrate the analysis of growth and business cycles.

In our model, both welfare and growth maximization imply constant tax rates over time. Such policies possess a high degree of political feasibility, given the sluggishness of the political process. In contrast, stabilization policies require frequent and precise changes in tax rates, which we regard as much less politically feasible. Moreover, stabilization requires flexibility in the government's budget constraint that may present additional political problems. Despite these issues, we continue to investigate the implications of stabilization policies for welfare, volatility and growth. Our view is that if the benefits of stabilization are found to be sufficiently large, then this may motivate reforms to the political process to accommodate the required flexibility. For example, stabilization policies might be accomplished through institutional changes, such as unemployment insurance that serve as automatic stabilizers, and thus do not require period by period legislation.

We find that stabilization policies can produce welfare levels that are nearly identical to welfare maximization policies. Furthermore, both welfare maximization and stabilization policies yield large welfare gains and modest growth losses relative to growth maximization policies. The latter finding can be attributed to excessive sav- 
ings that results from a policy that focuses singly on growth. Thus, our model suggests that welfare and stabilization policies are superior to a growth maximization policy.

Regarding the choice between stabilization or welfare maximization, additional criteria should be considered. Taylor (1980) argues that there is some better measure of utility that is too complicated to express which places a higher value on stabilization. However, our model highlights some important side issues associated with stabilization policies which reduce the attraction of Taylor's argument. We show that it may not be possible to stabilize all macroeconomic variables simultaneously even when the number of policy instruments is equal to the number of shocks. Thus there are many different reasonable stabilization polices. In addition, stabilizing a particular variable requires increased volatility of some other variable; thus there are destabilization costs. ${ }^{1}$ These results arise because the tools available to policy makers are unable to directly offset the random shocks, but instead must work in a more round about way. These side issues show that even with a Taylor criterion, a stabilization objective is ambiguous and may not dominate a welfare maximization policy.

The paper is organized as follows. In section 2 we describe the private sector and derive the associated decision roles. Section 3 derives an expression that governs the per capita economic growth rate of the economy. Section 4 describes the various fiscal objectives and derives the associated government policy rules. This section also describes many qualitative implications of the various policies. In section 5 , we calibrate the model in order to carry out quantitative analysis which is presented in section 6. Section 7 concludes.

\section{The Private Sector}

Our model combines the corporate and consumer sectors and focuses on a representative household that maximizes lifetime utility, subject to budget and production constraints. The household's objective is mathematically formulated as choosing

\footnotetext{
${ }^{1}$ Smyth (1963) and Christian (1984) also show that stabilization policies may lead to destabilizing outcomes.
} 


$$
\begin{aligned}
& \left\{c_{t}, l_{t}, y_{t}, i_{t}, k_{t+1},: t \geq 0\right\} \text { to maximize } \\
& \qquad E_{0} \sum_{t=0}^{\infty} \beta^{t} \log \left(c_{t}-B h_{t} l_{t}^{\gamma}\right)
\end{aligned}
$$

subject to

$$
\begin{gathered}
c_{t}+\left(1-\phi_{t} \tau_{t}\right) i_{t}=\left(1-\tau_{t}\right) y_{t}, \\
y_{t}=A_{0} k_{t}^{\theta}\left(h_{t} l_{t}\right)^{(1-\theta)} e^{z_{t}}, \\
k_{t+1}=A_{1} i_{t}^{\delta} k_{t}^{1-\delta} e^{v_{t}}
\end{gathered}
$$

where taste and technology parameters satisfy $0<\beta<1 ; 0 \leq B, 0<\gamma, 0<A_{i}$ for $i=1,2,0<\theta<1$ and $0<\delta<1$

Lifetime utility, given by (1), is the sum of discounted momentary utility values where utility is a function of choice variables $C_{b}$ the amount of goods consumed at time $t, l_{t}$, the amount of time allocated to productive activities, and state variable $h_{v}$ an index of knowledge. This form of the utility function can be interpreted as incorporating home production, as in Greenwood, Rogerson and Wright (1995). Several features of this utility function warrant comment. The presence of $h_{t}$ in (1) and (3) implies that productivity in the home and productivity in the market increase at the same rate. This ensures that $l_{t}$ remains stationary along the model's balanced growth path. The parameter $\gamma$ controls the elasticity of household labor supply. As $\gamma$ becomes very large, the level of labor supplied approaches one and the model reduces to one with a fixed labor supply.

Equation (2) is the temporal budget constraint, where $y_{t}$ denotes pre-tax income and is the tax rate. After tax income is allocated to consumption and investment, if. We allow for the possibility that a fraction $\emptyset_{t}$ of investment expenditures may be tax deductible. The variable $\emptyset_{t}$ is intended to capture the various elements of the tax code that encourage investment. These include, investment tax credits, depreciation allowances, and direct expensing of certain types of outlays, such as research and development expenditures.

Output is produced by combining capital, $k_{t}$, and effective labor, $h_{t} l_{\nu}$ in a Cobb Douglas technology given in (3). Knowledge augments the productive capacity of each hour spent working. Following Arrow (1962) and Romer (1986), it is assumed 
that knowledge grows proportionally to and as a by-product of accumulated private investment and research activities such that $h_{t}=\bar{k}_{t}$, where $\bar{k}_{t}$ is the average capital stock across households. Furthermore, since all households are identical, $\vec{k}_{t}=k_{t}$ in equilibrium. We assume that households exist in large numbers so that no individual household can affect $\bar{k}_{t}$. Thus, we impose the condition $h_{t}=\bar{k}_{t}=k_{t}$ after households make their decisions. Output is also affected by a random technology shock given by $e^{z_{t}}$, where $z_{t}=\alpha_{1} z_{t-1}+\epsilon_{1 t}, 0<\alpha_{1}<1$ and $\epsilon_{1 t}$ is independent $N\left(0, \sigma_{1}^{2}\right)$.

The capital stock evolves according to (4), which implies a nonlinear relationship between current investment and next period's capital. This nonlinear form can be interpreted as incorporating adjustment costs for new investment. ${ }^{2}$ We also allow for the possibility of shocks that directly impact capital accumulation. These shocks, represented by $e^{v t}$, can be interpreted as events that affect the economic value of existing capital, and thus, its usefulness in producing new capital. An example might be the oil price shocks of the 1970's that reduced the economic value of energy intensive equipment. The law of motion for $v_{t}$ is $v_{t}=\alpha_{2} v_{t-1}+\epsilon_{2 t}, 0<\alpha_{2}<1$, where $\epsilon_{2 t}$ is independent $N\left(0, \sigma_{2}^{2}\right)$.

Because the model is analytically tractable, standard techniques can be used to show that the household's optimal decision rules are

$$
\begin{gathered}
i_{t}=a_{0} \frac{\left(1-\tau_{t}\right)}{\left(1-\phi_{t} \tau_{t}\right)} y_{t}, \\
c_{t}=\left(1-a_{0}\right)\left(1-\tau_{t}\right) y_{t}, \\
l_{t}=\left[\frac{\left(1-\tau_{t}\right)(1-\theta) A_{0} e^{z_{t}}}{\gamma B}\right]^{\frac{1}{\gamma+\theta-1}},
\end{gathered}
$$

where $a_{0}=\frac{\beta \delta \theta}{1-\beta(1-\delta)}$. The derivation of these decision rules and other analytical results can be found in the appendix.

\section{The Per Capita Growth Rate}

One of our objectives is to study the effects of different fiscal policies on economic growth. In what follows, we derive a general expression for the economy's per capita

${ }^{2}$ This form has been used in applied work Hercowitz and Sampson (1991), Kocherlakota and Yi ( 1994) and Cassou and Lansing (1995), among others. 
growth rate which will remain valid under all policies. Using (3), (4), (5) and (7), it can be shown that the growth rate between time $t$ and time $t+1$ is given by

$$
\frac{k_{t+1}}{k_{t}}-1=A_{1} e^{v_{t}}\left[a_{0}\left(\frac{1-\theta}{\gamma B}\right)^{\frac{1-\theta}{\gamma+\theta-1}}\left(A_{0} e^{z_{t}}\right)^{\frac{\gamma}{\gamma+\theta-1}}\right]^{\delta} \frac{\left(1-\tau_{t}\right)^{\frac{\delta \gamma}{\gamma+\theta-1}}}{\left(1-\phi_{t} \tau_{t}\right)^{\delta}}-1 .
$$

In addition to computing the growth rate under the various policies, this expression is also used as the objective for the growth maximization policy.

\section{Fiscal Policy Objectives}

When economists or policy makers talk about reasonable macroeconomic objectives for the government, many possibilities arise. Among the most common are, welfare maximization, stabilization and growth maximization. Each of these objectives has its own merits and limitations. In this section, we characterize the government's optimal decision rules under each objective and examine the qualitative implications of each policy. Later, in Section 6, we undertake a quantitative analysis in a calibrated version of the model. We begin by considering the problem in which the government maximizes the welfare of the household. Next, we consider stabilization policies. We show that stabilization policies can accomplish a number of tasks, but may be unable to accomplish all desired tasks simultaneously. Thus, choices must be made as to what variables will be stabilized. We focus on two particular stabilization objectives: temporal utility stabilization and output stabilization. Finally, we investigate the growth maximization policy.

\subsection{Welfare Maximization}

Ramsey (1927) considered the problem of how the government should set up a commodity tax system to raise a desired amount of revenue, while minimizing welfare losses. In the dynamic version of the problem, the government chooses a sequence of taxes over time to finance an exogenous stream of spending, while maximizing social welfare. This is the formulation used by Lucas and Stokey (1983), Charnley (1986), Jones, Manuelli and Rossi (1993), Zhu (1992), Chari, Christiano, and Kehoe (1994), Cassou and Lansing ( 1995), and others. In this paper, we consider a variation on this 
this Ramsey problem which allows the government to recognize the way that required spending is determined by the level of output. We model government spending, $g_{v}$ as a constant fraction $\psi \geq 0$ of total output, such that

$$
d t=y_{t} .
$$

This formulation implies that government expenditures on goods and services increase in fixed proportion to the level of economic output. In formulating its policy, the government takes this relationship into account. ${ }^{3}$

We assume that the government balances its budget period by period. ${ }^{4}$ To finance expenditures, the government imposes a tax on income at the rate $\tau_{t}$. The government can also stimulate investment by allowing a portion of such spending to be tax deductible, as determined by $\emptyset_{t}$. The government budget constraint at time $t$ is

$$
g_{t}={ }_{t} y_{t}-\phi_{t} \tau_{t} i_{t}
$$

The government's decision problem can be mathematically formalized as choosing $\left\{\tau_{t}, \phi_{t}, g_{t}, c_{t}, l_{t}, y_{t}, i_{t}, k_{t+1}: t \geq 0\right\}$ to maximize (1) subject to (2), (3), (4), (5), (6), (7), (9) and (10). Because the model is analytically tractable, standard optimization procedures yield the following optimal policy rules under the welfare maximization regime:

$$
\begin{gathered}
\tau_{t}=\bar{\tau}=\frac{a_{1}+\psi-a_{0}}{1-a_{0}} . \\
\phi_{t}=\bar{\phi}=\frac{1}{\bar{\tau}}-\frac{a_{0}(1-\bar{\tau})}{a_{1} \bar{\tau}}
\end{gathered}
$$

${ }^{3}$ This formulation has slightly different implications than the traditional Ramsey problem in which government expenditures are viewed as completely exogenous by the policy maker. Here, the government understands that a policy which stimulates investment and output, also results in higher government spending, which does not contribute to either production or utility. Thus, the welfare maximizing policy calls for somewhat lowcr investment incentives than one where $g_{t}$ is viewed as exogenous.

${ }^{4}$ This assumption has been used by Barro (1990), Barro and Sala-i-Martin (1992), Glomm and Ravikumar (1994), Cassou and Lansing (1995) among others. We believe this may be a closer description of actual constraints than optimal tax studies which allow the government to borrow or lend large amounts. For instance. Chamley (1986) and Jones, Manuelli and Rossi (1993) find in models with no limits on debt, that optimal policy can result in the government lending large amounts of assets in the initial periods and then relying on interest from these assets to finance expenditures in later periods. 
where $a_{1}=\frac{\beta \delta(\gamma+\theta-1)(1-\psi)}{\gamma[1+\beta(\delta-1)]}$. Notice that the welfare maximizing policy calls for constant tax rates over time. This result is consistent with the tax smoothing arguments in Barro (1979).

\subsection{Temporal Utility Stabilization}

Stabilizing business cycle fluctuations has long been a concern of policy makers, and is often associated with a Keynesian view of government's role in the economy. Unfortunately, because the economy is very complicated and the policy tools very crude, it is impossible to stabilize all aggregate variables simultaneously. This means that choices must be made as to which of the many possible stabilization options are to be pursued. In what follows, we illustrate the diversity of stabilization rules by focusing on two particular stabilization schemes: temporal utility stabilization and output stabilization. We show that complete stabilization of either can be accomplished singly. However, simultaneous stabilization cannot be accomplished, even though the number of policy instruments is equal to the number of shocks. Furthermore, we show that each policy produces side effects in that some other economic variable becomes more variable.

In order for stabilization policies that involve changing tax rates to be feasible, some other variable in the government budget constraint must give. In practice, budgets are not balanced period by period and public debt is used to absorb the shocks. Rather, than deal with debt, we maintain the balanced budget condition, but allow $g_{t}$ to be determined as a residual which absorbs the revenue fluctuations associated with changing tax rates. Thus, we relax the constraint (9).

We begin our analysis of stabilization policies by considering a simple extension of the welfare maximizing problem in section 4.1. In particular, we assume the government sets the steady state levels of the policy variables equal to the values given in (11) and (12) and chooses taxes so that

$$
\begin{gathered}
\left(1-\tau_{l}\right)=\frac{(1-\bar{\tau})}{e^{z_{t}}} \\
\left(1-\phi_{t} \tau_{t}\right)=\left(e^{v_{l}}\right)^{\frac{1}{\delta}}(1-\bar{\phi} \bar{\tau}) .
\end{gathered}
$$


This policy is a bit of a hybrid in that it has the same steady state as the welfare maximization problem, but possesses features designed to reduce fluctuations in temporal utility.

The above policy rules require the government to react in a precise and immediate way to each shock as it hits the economy. It is likely, however, that political inertia would limit the size and scope of any fiscal response unless the tax code was specifically designed to automatically adjust to changing economic conditions. However, if the benefits of stabilization are sufficiently large, then it may be worthwhile for the government to adopt institutional changes that streamline the bureaucracy required to make changes to the tax law where automatic structures are not feasible.

To see that these rules will stabilize labor, consumption and therefore temporal utility, note that (7) and (13) imply that $l_{t}$ will be constant over time. Next, by combining (3), (4), (5), (13) and (14), it can be seen that random fluctuations in the capital stock are eliminated. This tax code is designed so that investment responds in exactly the right amount to offset the capital accumulation technology shock, $e^{v t}$. As a result, the tax code induces investment volatility in order to achieve capital stability. Now, because $k_{t}=h_{t}$ and $l_{t}$ are stabilized, (3) implies that the nonrandom part of $y_{t}$ is stabilized. Although the technology shock $e^{z t}$ still produces a fluctuating output stream, (13) implies that after tax income is completely smoothed. Equation (6) implies that $c_{t}$ is also stabilized. Since $c t, l_{t}$ and $k_{t}=h_{t}$ are all stabilized, temporal utility is also stabilized.

The above scheme highlights some weaknesses of the stabilization policies we consider. First, even when there arc as many policy tools as exogenous shocks, the government cannot stabilize all macroeconomic aggregates. Under the policy given by (13) and (14), $i_{t}$ and $y_{t}$ continue to fluctuate. Indeed fluctuations in $i_{t}$ actually increase. This occurs because the policy variables do not necessarily enter in a way that permits them to directly offset the random shocks. Instead, policy must attack the uncertainty in a round about way. Since it is impossible to stabilize all aggregate variables, some choice must be made as to which variables will be stabilized. In this example, we chose to stabilize temporal utility, while output was 
allowed to fluctuate. It could be reasonably argued that output stabilization is the more attract ive objective. In the next section, we consider an alternative scheme that is aimed at eliminating random fluctuations of output around trend.

\subsection{Output Stabilization}

Random fluctuations in output can be eliminated by the following combination of tax policies.

$$
\begin{gathered}
\left(1-\tau_{t}\right)=\frac{(1-\bar{\tau})}{\left(e^{z_{t}}\right)^{\frac{\gamma}{1-\theta}}} \\
\left(1-\phi_{t} \tau_{t}\right)=\frac{\left(1-\tau_{t}\right)}{(1-\bar{\tau})}\left(e^{v_{t}}\right)^{\frac{1}{\delta}}(1-\bar{\phi} \bar{\tau})
\end{gathered}
$$

Our analysis of this policy proceeds as follows. First, notice that (15) is constructed so that the current labor supply $l_{t}$ responds by exactly the right amount to offset the current output technology shock $e^{2 t}$. Next notice that (16) is constructed so that $i_{t}$ responds to offset the capital accumulation shock $e^{v t}$. The combination of (15) and (16) implies that future capital stocks are not affected by current shocks. Because the current shocks do not effect future capital stocks, which is the only way for the shocks to be transferred across time periods, the effects of current shocks on current and future output levels has been eliminated. Although, output has been stabilized, the labor input is now more variable and therefore temporal utility is also variable. Again, we see that there is an inability to stabilize all variables simultaneously and subjective decisions must be made about which of the many options should be pursued.

\subsection{Growth Maximization}

Policy makers seem to almost interchangeably view growth and welfare. Of course, high growth rates can produce very important welfare benefits such as an increase in the standard of living over time. However, some caution must be taken when designing policies to promote growth. It is well known that, high output levels driven by high savings rates need not imply high living standards if savings is in excess of the Golden Rule. Furthermore, monetary authorities may be concerned about possible inflationary pressure in high growth economies. Since our model includes only real variables, we do not address the latter concern. However, as we demonstrate 
below, growth maximizing policy can result in substantially lower welfare levels in comparison to other fiscal objectives.

To maintain comparability with the previous policies, we continue to impose (10) as the government budget constraint. Under the growth maximizing policy, the government chooses $\left\{\tau_{t}, \phi_{t}: t \underline{\theta}\right\}$ to maximize (8) subject to (10). Standard optimization techniques yield decision rules

$$
\begin{gathered}
\tau_{t}=\bar{\tau}^{g}=\frac{(\gamma+\theta-1)-a_{0} \gamma+(1-\theta) \psi}{\gamma\left(1-a_{0}\right)}, \\
\phi_{t}=\bar{\phi}^{g}=\frac{\psi-\bar{\tau}^{g}}{\bar{\tau}^{g}\left(\psi-\bar{\tau}^{g}-a_{0}\left(1-\bar{\tau}^{g}\right)\right)} .
\end{gathered}
$$

Notice that growth maximization calls for policy to remain constant over time, as in the welfare maximization problem of section 4.1.

\section{Calibration of the Model}

In general, parameters are assigned values based on empirically observed features of the U.S. economy. Three calibrating criteria are used. Some values are based on prior empirical findings, while others are assigned values so that the model's balanced growth path exhibits some characteristics that coincide with long-run observations for the postwar U.S. economy. Finally, the exogenous shock processes are estimated by using equilibrium conditions in the model and observed data to back out an implied sequence of shocks. This shock data is then used to estimate the stochastic structure.

Two of the parameters where assigned values based on prior empirical work. Following Greenwood, Hercowitz and Huffman (1988), we set $\gamma=1.60$, which implies that the intertemporal elasticity of substitution in labor supply $1 /(\gamma-1)$ is equal to 1.7. As noted by these authors, this value lies about midway in the range of empirical elasticity estimates. I.abor's share of output, $1-\theta=0.60$, is chosen based on empirical work by Christiano (1988), Ai and Cassou (1995), and others and is close to the value of 0.58 used by King, Plosser, and Rebelo (1988).

Six of the parameters were chosen so that the model's balanced growth path exhibits characteristics that correspond to long run averages for the U.S. economy from 1948 to 1993 . The value $\psi=0.218$ matches the average ratio of U.S. government 
spending to output over this period. ${ }^{5}$ The values for $\beta, \delta, B, A_{0}$. and $\mathbf{A}_{1}$ where chosen simultaneously in order to match the following five statistics. (1) The after-tax interest rate is 6.9\%, which is the value estimated by Cooley and Prescott (1995). (2) Households spend about one third of their time in market activities. (3) The investment to capital ratio, $\frac{i_{t}}{k_{t}}$, is 0.0834 . (4) The investment to output ratio, $\frac{i_{t}}{y_{t}}$, is 0.228 . $^{6}$ (5) The per capita growth rate is $1.841 \%$. In this matching process, steady state values for the model's tax rates need to be used. The steady state income tax rate was set equal to 0.364 which is the average of the observed ratio of total federal, state and local government receipts (Citibase series GGFR+GGSR+GGFSIN+GGSSIN) to GDP. This value is close to the 0.35 baseline value used by Greenwood and Huffman (1991 ). The investment subsidy, ø\&tt, includes a combination of depreciation allowances and investment tax credits and was set to 0.07 which is the baseline value used by Greenwood and Huffman (1991). This calibration process results in $\beta=0.985, \delta=0.0771, B=0.505, \mathrm{~A}_{\mathrm{o}}=0.706$ and $\mathrm{A}_{1}=1.233$.

Finally, the parameters governing the exogenous technology shock process were estimated by backing out implied series for $z_{t}$ and $v_{t}$ from the data, given the calibrated parameters above. These observed shock series were then used to estimate the first order autoregression processes for the model. This procedure resulted in $\alpha_{1}=0.867, \sigma_{\lambda}=0.0107, \alpha_{2}=0.343$ and $\sigma_{2}=0.0054$.

\section{Quantitative Policy Evaluation}

In this section we undertake a quantitative comparison of the different fiscal objectives. We compare policies based on their implications for business cycle characteristics, growth and welfare. The business cycle and growth comparisons are based on results from 1000 simulations of 46 periods under each policy while the welfare comparisons are based on 1000 simulations of 500 periods. A summary of the results is provided in Table 1 . The first panel in Table 1 presents information about simula-

${ }^{5}$ Data for this and other calculations were obtained from Citibase. The exception is the capital stock data, which was obtained from Fixed Reproducible Tangible Wealth in the United States, U.S. Department of Commerce (1993). Statistics based on capital stock data are for the period 1948 to 1992.

${ }^{6} \mathrm{We}$ include spending on consumer durables as part of investment. 
tions based on the baseline tax rates which were used to calibrate the model. These simulations show that the average growth rate is $1.85 \%$ which is close to the value we calibrated the model to. The baseline tax simulations illustrate an important feature of our model: the percentage standard deviations for output, consumption and investment are identical and these variables are perfectly correlated with one another. This is simply a reflection of the household decision rules (5) and (6) which show that with constant tax policy, $c_{t}$ and $i_{t}$ are constant fractions of total output $y_{t}$ Similar implications arise in the welfare maximizing and growth maximizing fiscal policies where tax policies are also constant.

The next four panels compare results from the different fiscal objectives. Using the parameters described in section 5, the welfare maximizing tax rates are $\tau_{t}=0.44$ and $\emptyset_{t}=1.23$ which imply an investment subsidy of $\emptyset_{t} \tau_{t}=.54$. Welfare maximizat ion calls for a large investment subsidy to offset household underinvest ment in human capital that is a result of our learning by doing externality. Notice that the constant tax rates implied by the welfare maximizing policy produce no change in the volatilities of the different economic variables. Thus, a welfare maximizing policy could not be considered an improvement based on a stabilization criterion. However, the large investment subsidy of the welfare maximization policy induces a rapid rate of growth and a large welfare gain over the baseline tax policy. ${ }^{7}$ Welfare gains of this magnitude were also reported by Jones, Manuelli and Rossi (1993) and are due to the endogeneity of the growth rate.

Because the temporal utility stabilization policy works around the welfare maximizing tax rates, it also implies a sizable improvement in welfare and growth over the baseline policy. Interestingly, the temporal utility stabilization policy yields very similar welfare levels as the welfare maximizing policy. This is not surprising, since both policies use the same steady state values for $\tau_{t}$ and $\emptyset_{t}$. As expected, the temporal utility stabilization policy does eliminate fluctuations in consumption, labor

\footnotetext{
${ }^{7}$ The welfare gain in percent is computed according to the formula $100\left\{\exp \left[(1-\beta)\left(V_{p}-V_{b}\right)\right]-1\right\}$, where $V_{b}$ is lifetimc utility under the baseline policy and $V_{p}$ is lifetime utility under the altcrnatice fiscal policy. This calculation is approximately the percentage by which the baseline model path for $c_{t}$ must be raised in order to achieve the utility level calculated under the alternative fiscal policies, where the approximation is due to random fluctuations about the balanced growth path.
} 
and leisure. Furthermore, this is accomplished by inducing more variability in investment as reflected in the standard deviation of $i_{t}$ which increases from $1.19 \%$ under the baseline policy to $5.49 \%$. The increased investment variability also shows that a temporal utility stabilization policy is unable to stabilize everything simultaneously even though there are two policy tools and two sources of random fluctuations.

The implications for output stabilization are very similar to those of the temporal utility stabilization policy. As in the temporal utility stabilization policy, there is a sizable improvement in growth and utility over the baseline tax system, but virtually identical growth and welfare levels as in the welfare maximization policy. Table 1 also shows that output stabilization has accomplished its objective. However, in this case, the cost is somewhat higher because now, not only has investment volatility increased, but consumption, labor, and leisure volatility have also increased.

The growth maximization policy implies $\tau_{t}=.56$ and $\varnothing_{t}=1.25$ and an investment subsidy of $\emptyset_{t t}=0.70$. As expected, growth maximization calls for larger investment incentives in comparison to welfare maximization. Table 1 shows that growth maximization results in a welfare gain over the baseline tax system. However, this gain is considerably less than the gain obtained under the other three policies. This result indicates that growth maximization encourages savings in excess of the Golden Rule level. This highlights a potential drawback of policies which focuses singly on promoting output growth.

\section{Conclusion}

This paper compared a variety of government fiscal policy objectives. We found that stabilization policies can produce welfare levels that are virtually identical to those of welfare maximization if the steady state tax polices are appropriately chosen. Moreover, both welfare maximization and stabilization policies yield large welfare gains and modest growth losses relative to a growth maximization policy.

Because welfare maximization and stabilization policies can produce comparable welfare levels and growth rates, choosing between them must be based on a number of side issues regarding stabilization policies. It was shown that; (1) it is not 
possible to stabilize all macroeconomic variables simultaneously even when there are as many policy variables as there are exogenous shocks; (2) stabilizing a particular variable requires increased volatility of some other variable; (3) stabilization requires some flexibility regarding the government's budget constraint; and, (4) stabilization requires the government to respond in a precise and immediate way to shocks as they hit the economy. Even if we assume that issues (3) and (4) can be politically managed, issues (1) and (2) show that some priorities as to which variables will be stabilized must be set and what level of volatility for the absorbing variables will be tolerated. 


\section{References}

[1] Ai, Chunrong and Steven P. Cassou. (1995). "A Normative Analysis of Public Capital," Applied Economics, 27, 1201-1209.

[2] Arrow, Kenneth J. (1962). "The Economic Implications of Learning by Doing," Review of Economic Studies, 29, 155-173.

[3] Baxter, Marianne and Robert G. King. (1995). "Measuring Business Cycles: Approximate Band-Pass Filters for Economic Time Series, National Bureau of Economic Research, Working Paper No. 5022.

[4] Barro, Robert J. (1979). "On the Determination of Public Debt," Journal of Political Economy, 87, 940-971.

[5] (1990). "Government Spending in a Simple Model of Endogenous Growth;" Journal of Political Economy, 98, S103-125.

[6] and Xavier Sala-i-Martin. (1992). "Public Finance in Models of Economic Growth," Review of Economic Studies, 89, 645-661.

[7] Cassou, Steven P. and Kevin J. Lansing. (1995). "Optimal Fiscal Policy, Public Capital, and the Productivity Slowdown," Federal Reserve Bank of Cleveland, Working Paper 9509.

[8] Chamley, Christopher. (1986). "Optimal Taxation of Capital Income in a General Equilibrium Model with Infinite Lives," Econometrica, 54, 607-22.

[9] Chari, V. V., Lawrence J. Christiano, and Patrick J. Kehoe. (1994). "Optimal Fiscal Policy in a Business Cycle Model," Journal of Political Economy, 102, 617-652.

[10] Christiano, Lawrence J. (1984). "A Reexamination of the Theory of Automatic Stabilizers," Carnegie-Rochester Conference Series on Public Policy, 20, 147206.

[11] _ (1988). "Why Does Inventory Investment Fluctuate So Much?," Journal of Monetary Economics, 21, 247-280.

[12] Cooley, Thomas F. and Edward C. Prescott. (1995). "Economic Growth and Business Cycles," in T. F. Cooley, ed., Frontiers of Business Cycle Research. Princeton N.J: Princeton University Press.

[13] Glomm, Gerhard and B. Ravikumar. (1994). "Public Investment in Infrastructure in a Simple Growth Model," Journal of Economic Dynamics and Control, $18,1173-1187$.

[14] Greenwood, Jeremy, Zvi Hercowitz, and Gregory W. Huffman. (1988). "Investment, Capacity Utilization, and the Real Business Cycle," American Economic Review, 78, 402-417.

[15] Greenwood, Jeremy and Gregory W. Huffman. (1991). "Tax Analysis in a Real Business Cycle Model: On Measuring Harberger Triangles and Okun Gaps," Journal of Monetary Economics, 27, 167-90. 
[16] Greenwood, Jeremy, Richard Rogerson, and Randall Wright. (1995). "Household Production in Real Business Cycle Theory," in T. F. Cooley, ed., Frontiers of Business Cycle Research. Princeton, NJ: Princeton University Press.

[17] Hercowitz, Zvi, and Michael Sampson. (1991)." Output Growth, the Real Wage, and Employment Fluctuations," American Economic Review, 81, 1215-1237.

[18] Jones, Larry E., Rodolfo Manuelli, and Peter E. Rossi. (1993). Optimal Taxation in Models of Endogenous Growth," Journal of Political Economy, 101, 485-517.

[19] King, Robert G., Charles I. Plosser, and Sergio T. Rebelo. (1988). "Production, Growth and Business Cycles I. The Basic Neoclassical Model," Journal of Monetary Economics, 21, 195-232.

[20] Kocherlakota, Narayana R. and Kei-Mu Yi. (1995). "Can Convergence Regressions Distinguish Between Exogenous and Endogenous Growth Models? ," Economics Letters, 49, 211-215.

[21] Lucas, Robert E., Jr. and Nancy L. Stokey. (1983). "Optimal Fiscal and Monetary Policy in an Economy Without Capital," Journal of Monetary Economics, $12,55-94$.

[22] Ramsey, Frank P. (1927). "A Contribution to the Theory of Taxation," Economic Journal, 37, 47-61.

[23] Romer, Paul. (1986). "Increasing Returns and Long-Run Growth," Journal of Political Economy, 94, 1002-1037.

[24] Smyth, D.J. (1963). “Can 'Automatic Stabilizers' be Destabilizing?," Public Finance, 18, 357-363.

[25] Taylor, John B. (1980). "Comment on Kydland and Prescott," in S. Fischer ed., Rational Expectations and Economic Policy. Chicago IL: University of Chicago Press.

[26] Zhu, Xiaodong. (1992). "Optimal Fiscal Policy in a Stochastic Growth Model," Journal of Economic Theory, 58, 250-289. 
Table 1: Economic Performance of Simulated Fiscal Policies

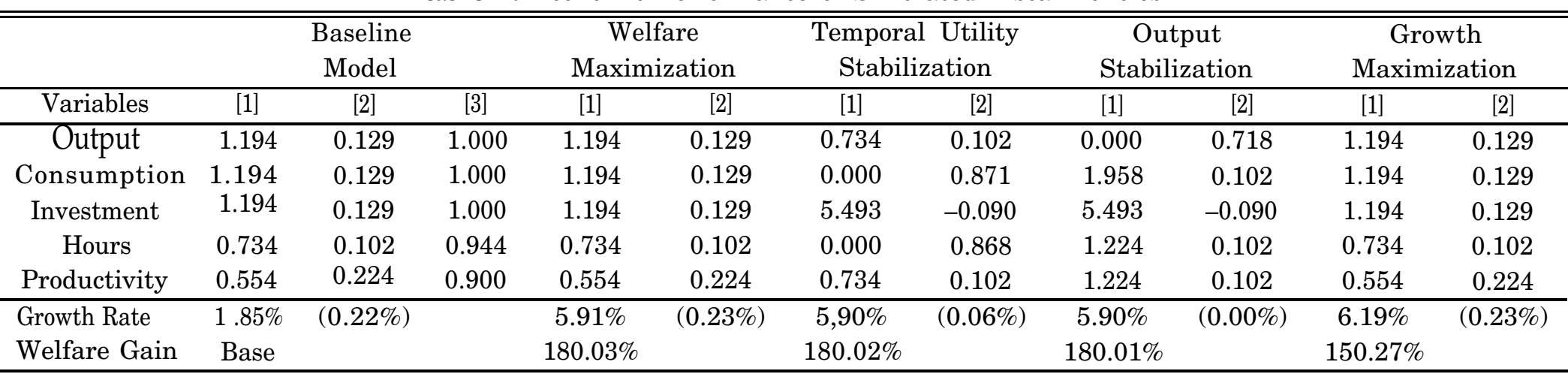

Notes: [1] Percentage Standard Deviation, [2] First-order autocorrelation, [3] Correlation with output.

Numbers in parenthesis indicate standard deviations. Business cycle statistics are based on logged and detrended variables, where detrending is accomplished using the Hodrick-Prescott filter with smoothing parameter equal to 10, as recommended by Baxter and King (1995) for annual data. 


\section{A Appendix}

This appendix provides the derivations for the analytical results presented in the paper.

\section{A.1 The Household's Problem}

Write the problem as choosing $\left\{c_{i}, l_{t}, y_{t}, i_{t}, k_{t+1}: t \geq 0\right\}$ to maximize

$$
E_{0} \sum_{t=0}^{\infty} \beta^{t} \log \left(c_{t}-B h_{t} l_{t}^{\gamma}\right)
$$

subject to

$$
\begin{aligned}
c_{t}+\left(1-\phi_{t} \tau_{t}\right) i_{t} & =\left(1-\tau_{t}\right) y_{t} \\
y_{t} & =A_{0} k_{t}^{\theta}\left(h_{t} l_{t}\right)^{(1-\theta)} e^{z_{t}} \\
k_{t+1} & =A_{1} i_{t}^{\delta} k_{t}^{1-\delta} e^{v_{t}}
\end{aligned}
$$

The Lagrangian for this problem can be written as

$$
\begin{aligned}
L(\cdot)= & \sum_{t=0}^{\infty} \beta^{t}\left\{\log \left(c_{t}-B h_{t} l_{t}^{\gamma}\right)+\lambda_{t}\left[\left(1-\tau_{t}\right)\left(A_{0} k_{t}^{\theta}\left(h_{t} l_{t}\right)^{1-\theta}\right) e^{z_{t}}-c_{t}\right.\right. \\
& \left.\left.-\left(1-\phi_{t} \tau_{t}\right) k_{t+1}^{\frac{1}{\delta}}\left(A_{1} e^{v_{t}}\right)^{\frac{-1}{\delta}} k_{t}^{\frac{\delta-1}{\delta}}\right]\right\} .
\end{aligned}
$$

The first order conditions are

$$
\begin{aligned}
\frac{\partial L(\cdot)}{\partial c_{t}}= & \frac{1}{c_{t}-B h_{t} l_{t}^{\gamma}}-\lambda_{t}=0 \\
\frac{\partial L(\cdot)}{\partial l_{t}}= & \frac{-\gamma B h_{t} l_{t}^{\gamma-1}}{c_{t}-B h_{t} l_{t}^{\gamma}}+\lambda_{t}\left(1-\tau_{t}\right)(1-\theta) \frac{y_{t}}{l_{t}}=0 \\
\frac{\partial L(\cdot)}{\partial k_{t+1}}= & -\lambda_{t}\left(1-\phi_{t} \tau_{t}\right)\left(\frac{1}{\delta}\right)\left(\frac{i_{t}}{k_{t+1}}\right)+ \\
& \beta \lambda_{t+1}\left[\left(1-\tau_{t+1}\right) 0 \frac{y_{t+1}}{k_{t+1}}-\left(1-\phi_{t+1} \tau_{t+1}\right)\left(\frac{\delta-1}{\delta}\right)\left(\frac{i_{t+1}}{k_{t+1}}\right)\right]=0 \\
\frac{\partial L(\cdot)}{\partial \lambda_{t}}= & \left(1-\tau_{t}\right) y_{t}-c_{t}-\left(1-\phi_{t} \tau_{t}\right) i_{t}=0
\end{aligned}
$$


To find the decision rules we use the method of undetermined coefficients. We guess the functional forms

$$
\begin{aligned}
i_{t} & =a_{0} \frac{\left(1-\tau_{t}\right)}{\left(1-\phi_{t} \tau_{t}\right)} y_{t}, \\
\frac{1}{\lambda_{t}} & =b_{0}\left(1-\tau_{t}\right) y_{t},
\end{aligned}
$$

where $a_{0}$ and $b_{0}$ are constants to be determined. Substituting these into (21) and solving for $a_{0}$ gives

$$
a_{0}=\frac{\beta \delta \theta}{1-\beta(1-\delta)} .
$$

To find the consumption decision rule substitute (23) into (22) and solve for $c_{t}$ to get

$$
c_{t}=\left(1-a_{0}\right)\left(1-\tau_{t}\right) y_{t}
$$

We can interpret $1-a_{0}$ as the marginal propensity to consume out of after-tax income.

To find the labor decision rule first substitute (19) into (20) and make use of (3) to get

$$
\gamma B h_{t} l_{t}^{\gamma}=\left(1-\tau_{t}\right)(1-\theta) A_{0} k_{t}^{\theta}\left(h_{t} l_{t}\right)^{1-\theta} e^{z_{t}} .
$$

Next make use of $h_{t}=\bar{k}_{t}=k_{t}$ and solve for $l_{t}$ to obtain

$$
l_{t}=\left[\frac{\left(1-\tau_{t}\right)(1-\theta) A_{0} e^{z_{t}}}{\gamma B}\right]^{\frac{1}{\gamma+\theta-1}}
$$

Finally, we need to verify that our guess was correct by verifying that $b_{0}$ is, in fact, a constant. To do this, substitute (24) into (19) to obtain

$$
c_{t}-B h_{t} l_{t}^{\gamma}=\cdot b_{0}\left(1-\tau_{t}\right) y_{t}
$$

Using (6) gives

$$
\left(1-a_{0}\right)\left(1-\tau_{t}\right) y_{t}-B h_{t} l_{t}^{\gamma}=b_{0}\left(1-\tau_{t}\right) y_{t}
$$

Next substitute ( 19) into (20) to obtain

$$
B h_{t} l_{t}^{2}=\frac{(1-\theta)\left(1-\tau_{t}\right)}{\gamma} y_{t}
$$

Substituting (28) into (27) and solving for $b_{0}$ yields

$$
b_{0}=\left(1-a_{0}-\frac{1-\theta}{\gamma}\right)
$$

which is a constant and thus confirms our guess. 


\section{A.2 The Per Capita Growth Rate}

To find the growth rate substitute (3) into (5) and use (7) to obtain

$$
i_{t}=a_{0}\left(\frac{\left(1-\tau_{t}\right)}{\left(1-\phi_{t} \tau_{t}\right)}\right) A_{0} k_{t}\left(\frac{\left(1-\tau_{t}\right)(1-\theta) A_{0} e^{z_{t}}}{\gamma B}\right)^{\frac{1-\theta}{\gamma+\theta-1}} e^{z_{t}} .
$$

Substituting this into (4) yields

$$
k_{t+1}=A_{1} e^{\nu_{t}} k_{t}^{1-\delta}\left[\left(\frac{a_{0}}{1-\phi_{t} \tau_{t}}\right)\left(\frac{1-\theta}{\gamma B}\right)^{\frac{1-\theta}{\gamma+\theta-1}}\left(\left(1-\tau_{t}\right) A_{0} e^{z_{t}}\right)^{\frac{\gamma}{\gamma+\theta-1}} k_{t}\right]^{\delta}
$$

which implies

$$
\frac{k_{t+1}}{k_{t}}=A_{1} e^{v_{t}}\left[a_{0}\left(\frac{1-\theta}{\gamma B}\right)^{\frac{1-\theta}{\gamma+\theta-1}}\left(A_{0} e^{z_{t}}\right)^{\frac{\gamma}{\gamma+\theta-1}}\right]^{\delta} \frac{\left(1-\tau_{t}\right)^{\frac{\varepsilon_{\gamma}}{\gamma+\theta-1}}}{\left(1-\phi_{t} \tau_{t}\right)^{\delta}} .
$$

The growth rate between time $t$ and time $t+1$ is thus given by

$$
A_{1} e^{v_{t}}\left[a_{0}\left(\frac{1-\theta}{\gamma B}\right)^{\frac{1-\theta}{\gamma+\theta-1}}\left(A_{0} e^{z_{t}}\right)^{\frac{\gamma}{\gamma+\theta-1}}\right]^{\delta} \frac{\left(1-\tau_{t}\right)^{\frac{\delta \gamma}{\gamma+\theta-1}}}{\left(1-\phi_{t} \tau_{t}\right)^{\delta}}-1
$$

\section{A.3 The Government's Problem: Welfare Maximization}

The government's optimization problem is to choose $\left\{\tau_{t}, \phi_{t}, g_{t}, c_{t}, l_{t}, y_{t}, i_{t}, k_{t+1},: t \geq\right.$ O\} to maximize

$$
E_{0} \sum_{t=0}^{\infty} \beta^{t} \log \left(c_{t}-B h_{t} l_{t}^{\gamma}\right)
$$

subject to

$$
\begin{aligned}
c_{t}+\left(1-\phi_{t} \tau_{t}\right) i_{t} & =\left(1-\tau_{t}\right) y_{t}, \\
y_{t} & =A_{0} k_{t}^{\theta}\left(h_{t} l_{t}\right)^{(1-\theta)} e^{z_{t}}, \\
k_{t+1} & =A_{1} i_{t}^{\delta} k_{t}^{1-\delta} e^{v_{t}} \\
i_{t} & =a_{0} \frac{\left(1-\tau_{t}\right)}{\left(1-\phi_{t} \tau_{t}\right)} y_{t}, \\
c_{t} & =\left(1-a_{0}\right)\left(1-\tau_{t}\right) y_{t} \\
l_{t} & =\left[\frac{\left(1-\tau_{t}\right)(1-\theta) A_{0} e^{z_{t}}}{\gamma B}\right]^{\frac{1}{\gamma+\theta-1}}, \\
g_{t} & =\psi y_{t}, \\
g, & \tau_{t} y_{t}-\phi_{t} \tau_{t} i_{t} .
\end{aligned}
$$


It will be useful to reduce the number of constraints by eliminating some of the variables. First note that (5) implies

$$
\phi_{t} \tau_{t} i_{t}=i_{t}-a_{0}\left(1-\tau_{t}\right) y_{t}
$$

Substituting the above expression into (10) and using (9) yields

$$
y_{t}\left[a_{0}+\tau_{t}\left(1-a_{0}\right)-\psi\right]-i_{t}=0
$$

Next, use (26) to eliminate $c_{t}-B h_{t} l_{t}^{\gamma}$ from the utility function, (3) to eliminate $y_{v}$ (4) to eliminate $i_{v}$, and (7) to eliminate $l_{t}$. These substitutions reduce the choice set to $\left\{\tau_{t}, k_{t+1}: t \geq 0\right\}$. The Lagrangian is

$$
\begin{aligned}
L_{g}(\cdot)= & \sum_{t=0}^{\infty} \beta^{t}\left\{\log \left(b_{0}\left(1-\tau_{t}\right) A_{0} k_{t}\left[\frac{\left(1-\tau_{t}\right)(1-\theta) A_{0} e^{z_{t}}}{\gamma B}\right]^{\frac{1-\theta}{\gamma+\theta-1}} e^{z_{t}}\right)\right. \\
& +\lambda_{g, t}\left(A_{0} k_{t}\left[\frac{\left(1-\tau_{t}\right)(1-\theta) A_{0} e^{z_{t}}}{\gamma B}\right]^{\frac{1-\theta}{\gamma+\theta-1}} e^{z_{t}}\left[a_{0}+\tau_{t}\left(1-a_{0}\right)-\psi\right]\right. \\
& \left.\left.-k_{t+1}^{\frac{1}{\delta}}\left(A_{1} e^{v_{t}}\right)^{\frac{-1}{\delta}} k_{t}^{\frac{\delta-1}{\delta}}\right)\right\}
\end{aligned}
$$

The first-order conditions are

$$
\begin{aligned}
\frac{\partial L_{g}(\cdot)}{\partial \tau_{t}}= & \frac{-\gamma}{\left(1-\tau_{t}\right)(\gamma+\theta-1)}+ \\
& \lambda_{g, t}\left[\frac{-(1-\theta) y_{t}\left[a_{0}+\tau_{t}\left(1-a_{0}\right)-\psi\right]}{(\gamma+\theta-1)\left(1-\tau_{t}\right)}+y_{t}\left(1-a_{0}\right)\right]=0 \\
\frac{\partial L_{g}(\cdot)}{\partial k_{t+1}}= & -\lambda_{g, t}\left(\frac{1}{\delta}\right) \frac{i_{t}}{k_{t+1}}+\frac{\beta}{k_{t+1}}+ \\
& \lambda_{g, t+1} \beta\left[\frac{y_{t+1}}{k_{t+1}}\left[a_{0}+\tau_{t+1}\left(1-a_{0}\right)-\psi\right]-\left(\frac{\delta-1}{\delta}\right) \frac{i_{t+1}}{k_{t+1}}\right]=0, \\
\frac{\partial L_{g}(\cdot)}{\partial \lambda_{g, t}}= & y_{t}\left[a_{0}+\tau_{t}\left(1-a_{0}\right)-\psi\right]-i_{t}=0 .
\end{aligned}
$$

To find the decision rules, we again use the method of undetermined coefficients. We guess the functional forms

$$
i_{t}=a_{1} y_{t}
$$




$$
\begin{aligned}
\frac{1}{\lambda_{g, t}} & =b_{1} y_{t}, \\
\tau_{t} & =\bar{\tau}
\end{aligned}
$$

where $a_{1}, b_{1}$, and $\bar{\tau}$ are constants to be determined.

Begin by substituting (32) and (34) into (31) and to obtain

$$
a_{0}+\bar{\tau}\left(1-a_{0}\right)-\psi=a_{1}
$$

Next substitute (32), (33) and (34) into (30) to obtain

$$
\frac{-a_{1}}{\delta}+\beta b_{1}+\beta\left[a_{0}+\bar{\tau}\left(1-a_{0}\right)-\psi\right]-\frac{\beta(\delta-1) a_{1}}{\delta}=0 .
$$

Substituting for $a_{0}+\bar{\tau}\left(1-a_{0}\right)-\psi$ from (35) into the above expression and solving for $b_{1}$ yields

$$
b_{1}=\frac{a_{1}(1-\beta)}{\delta \beta}
$$

Next, note that (35) can be rearranged to obtain (31), which then implies

$$
\bar{\tau}=\frac{a_{1}+\psi-a_{0}}{1-a_{0}}
$$

or

$$
1-\bar{\tau}=\frac{1-a_{1}-\psi}{1-a_{0}} .
$$

Finally, substitute (33) and (34) into (29) to obtain

$$
\frac{-\gamma b_{1}}{(1-\bar{\tau})(\gamma+\theta-1)}-\frac{(1-\theta)\left(a_{0}+\bar{\tau}\left(1-a_{0}\right)-\psi\right)}{(\gamma+\theta-1)(1-\bar{\tau})}+\left(1-a_{0}\right)=0 .
$$

Now substituting (36), (35) and (38) into the above expression, and solving for $a_{1}$ yields

$$
a_{1}=\frac{\beta \delta(\gamma+\theta-1)(1-\psi)}{\gamma[1+\beta(\delta-1)]} .
$$

Note that $a_{1}$ can be used in (36) to obtain $b_{1}$, and can also be used in (38) to get $\bar{\tau}$. All are constant, which confirms our guess.

To find the welfare maximizing $\phi_{\ell}$ use (5) to obtain

$$
\phi_{t}=\frac{1}{\bar{\tau}}-\frac{a_{0}}{a_{1}} \frac{(1-\bar{\tau})}{\bar{\tau}}
$$

which is also a constant, denoted by $\bar{\phi}$. 


\section{A.4 The Government's Problem: Growth Maximization}

The government problem is to choose $\left\{\tau_{t}, \phi_{t}: t \geq 0\right\}$ to maximize

$$
A_{1} e^{v_{t}}\left[a_{0}\left(\frac{1-\theta}{\gamma B}\right)^{\frac{1-\theta}{\gamma+\theta-1}}\left(A_{0} e^{z_{t}}\right)^{\frac{\gamma}{\gamma+\theta-1}}\right]^{\delta} \frac{\left(1-\tau_{t}\right)^{\frac{\delta \gamma}{\gamma+\theta-1}}}{\left(1-\phi_{t} \tau_{t}\right)^{\delta}}-1
$$

subject to

$$
\begin{aligned}
\dot{g}_{t} & =\psi y_{t}, \\
g_{t} & =\tau_{t} y_{t}-\phi_{t} \tau_{t} i_{t} .
\end{aligned}
$$

Rather than use a Lagrangian, it is simple enough to rearrange (10) and eliminate $\emptyset_{t}$ from the objective function. To do this, substitute (5) and (9) into (10) and rearrange to obtain

$$
\phi_{t} \tau_{t}=\frac{\psi-\tau_{t}}{\psi-\tau_{t}-a_{0}\left(1-\tau_{t}\right)}
$$

or

$$
\left(1-\phi_{t} \tau_{t}\right)=\frac{a_{0}\left(\tau_{t}-1\right)}{\psi-\tau_{t}-a_{0}\left(1-\tau_{t}\right)}
$$

By substituting (40) into (8), rearranging, and ignoring the constant terms and exogenous shocks, the transformed objective can be written as

$$
\left[a_{0}-\psi+\tau_{t}\left(1-a_{0}\right)\right]\left(1-\tau_{t}\right)^{\frac{(1-\theta)}{\gamma+\theta-1}}
$$

The above expression implies that the growth maximizing tax decision rule is given by

$$
\tau_{t}=\bar{\tau}^{9}=\frac{(\gamma+\theta-1)-a_{0} \gamma+(1-\theta) \psi}{\gamma\left(1-a_{0}\right)} .
$$

Now rearrange (39) to obtain

$$
\phi_{t}=\bar{\phi}^{g}=\frac{\psi-\bar{\tau}^{g}}{\bar{\tau}^{g}\left(\psi-\bar{\tau}^{g}-a_{0}\left(1-\bar{\tau}^{g}\right)\right)} .
$$

Note that both policy variables are constant as in the welfare maximization problem. 